\title{
EFEITO DA CALAGEM E INOCULAÇÃO DE SABIÁ EM SOLO DA MATA ÚMIDA E DO SEMI-ÁRIDO DE PERNAMBUCO ${ }^{1}$
}

\author{
NEWTON PEREIRA STAMFORD² e RICARDO ALENCAR DA SILVA ${ }^{3}$
}

\begin{abstract}
RESUMO - Realizou-se um experimento, usando solo álico da Zona da Mata e do Semi-Árido do Estado de Pernambuco, com o objetivo de avaliar o efeito da calagem $\left(0,3\right.$ e 6 t ha $\left.^{-1}\right)$ e da inoculação das estirpes de rizóbio: NFB 539, NFB 577 e NFB 578, previamente selecionadas para sabiá (Mimosa caesalpiniaefolia) em meio de cultura ácido. Adicionaram-se tratamentos sem inoculação, sem e com adição de $\mathrm{N}$ mineral (100 $\left.\mathrm{kg} \mathrm{ha}^{-1}\right)$, para fins comparativos. O experimento seguiu o esquema fatorial $2 \times 3 \times 5$, no delineamento em blocos ao acaso, com quatro repetições. As plantas foram colhidas 110 dias após a emergência (DAE). A inoculação de rizóbio, em todos os níveis de calagem, mostrou efeito significativo nos parâmetros avaliados. No nível de $3 \mathrm{tha}^{-1}$ não houve efeito da calagem, porém a adição de $6 \mathrm{tha}^{-1}$ de calcário reduziu o peso de matéria seca, o $\mathrm{N}$ total na parte aérea, a nodulação e a atividade da nitrogenase. $\mathrm{O}$ baixo $\mathrm{pH}$ e $\mathrm{Al}^{3+}$ do solo não prejudicou a fixação do $\mathrm{N}_{2}$, e o crescimento das plantas que receberam o inóculo. Portanto, torna-se desnecessária a calagem no cultivo de sabiá em solos ácidos, quando usadas estirpes selecionadas visando à resistência a acidez.
\end{abstract}

Termos para indexação: calcário, fixação do $\mathrm{N}_{2}$, Mimosa caesalpiniaefolia, rizóbio, solos álicos.

\section{EFFECT OF LIME AND INOCULATION OF MIMOSA CAESALPINIAEFOLIA \\ IN ACID SOIL OF THE FOREST ZONE AND SEMIARID REGION OF PERNAMBUCO, BRAZIL}

\begin{abstract}
An experiment was carried out in order to evaluate the effect of liming $\left(0,3\right.$ and 6.0 ton ha $\left.{ }^{-1}\right)$ in two alic soils of humid forest zone and semiarid region of the State of Pernambuco, Brazil, and rhizobia inoculation with strains NFB 539, NFB 577 and NFB 578, selected to Mimosa caesalpiniaefolia in previous assays with culture media using crescent levels of $\mathrm{Al}^{3+}$ and acidity. Treatments without inoculation with and without $\mathrm{N}$ addition $\left(100 \mathrm{~kg} \mathrm{ha}^{-1}\right)$ were included. A factorial $2 \times 3 \times 5$ was used in a randomized block design with four replicates. Plants were harvested at 110 days after emergence (DAE). Rhizobia inoculation showed significative effect regarding all parameters evaluated, at the lime levels used. M. caesalpiniaefolia did not respond to liming, however when used the level 6.0 ton $\mathrm{ha}^{-1}$, reduction in dry matter, $\mathrm{N}$ total uptake, nodulation and nitrogenase activity occurred. The low $\mathrm{pH}$ and high $\mathrm{Al}^{3+}$ in the natural soil did not promote injurious effect on $\mathrm{N}_{2}$ fixation and on growth of plants inoculated, showing that lime addition is not necessary to M. caesalpiniaefolia tree legume cropped in acid soils when strains selected to acidity are used.
\end{abstract}

Index terms: lime, $\mathrm{N}_{2}$ fixation, Mimosa caesalpiniaefolia, Rhizobium, alic soils.

\section{INTRODUÇÃO}

A agricultura moderna e auto-sustentável deve ser fundamentada na redução dos custos da produ-

\footnotetext{
${ }^{1}$ Aceito para publicação em 7 de junho de 1999. Extraído da dissertação de mestrado apresentada pelo segundo autor à UFRPE, Recife, PE.

${ }^{2}$ Eng. Agrôn., Ph.D., Prof. Titular, Dep. de Agronomia, UFRPE, CEP 52171-900 Recife, PE. Bolsista do CNPq. E-mail: newtonps@novaera.com.br

${ }^{3}$ Eng. Agrôn., M.Sc., Dep. de Agronomia, UFRPE.
}

ção e na preservação do meio ambiente, e a utilização de processos microbiológicos visando ao aumento da disponibilidade de nutrientes torna-se necessária, notadamente o uso do nitrogênio através da fixação biológica (Siqueira, 1983; Stamford et al., 1997).

No Nordeste ocorrem áreas com problemas de acidez, tanto na região semi-árida (Serra do Araripe), por fatores pedológicos, como na Zona da Mata Úmida dos tabuleiros costeiros, pela elevada precipitação. Nessas regiões ocorriam florestas natu- 
rais, e atualmente encontram-se sem vegetação, sujeitas a se tornarem verdadeiros desertos.

As pastagens naturais no Nordeste podem ser substancialmente ampliadas e melhoradas com o uso adequado de leguminosas arbóreas com alto valor protéico e capacidade de suporte (Bêde et al., 1985). Nativa da região semi-árida, o sabiá (Mimosa caesalpiniaefolia Benth) é uma das leguminosas arbóreas com grande potencial graças a sua resistência a estiagens prolongadas, seu rápido crescimento (Almeida et al., 1986) e alto teor protéico (Stamford et al., 1997), sendo indispensável em qualquer programa de reflorestamento na região semi-árida.

Para um crescimento adequado das leguminosas arbóreas, é necessário o estabelecimento de uma simbiose eficiente e ativa, e a inoculação de estirpe adequada de rizóbio ajuda a planta a desenvolver-se em solos deficientes em N (Blair et al., 1988). Em solos ácidos, a toxidez do Al tem sido apontada como uma das principais causas do insucesso do estabelecimento de leguminosas, pois pode prejudicar tanto o crescimento da planta como também o processo da fixação do $\mathrm{N}_{2}$ (Duguma et al., 1988).

Por causa da grande diversidade existente na população de rizóbio nativo, tem sido possível a obtenção de estirpes adaptadas às condições de acidez (De-Polli et al., 1988). Chen et al. (1991) observaram que as estirpes mais tolerantes à acidez e ao $\mathrm{Al}$ em meio de cultura foram também as que mostraram melhor sobrevivência em solos ácidos.

A incorporação de calcário aos solos ácidos cultivados com leguminosas vem mostrando resultados divergentes (Assis Júnior et al., 1986; Stamford \& Costa, 1991), e pode até ser antieconômica (Chen et al., 1991). Norris (1967) afirma que as vantagens da calagem para as leguminosas de clima temperado nem sempre são válidas para as leguminosas tropicais.

Portanto se faz necessário a obtenção de estirpes de rizóbio tolerantes a baixo $\mathrm{pH}$ e a $\mathrm{Al}$ tóxico, para possibilitar o desenvolvimento de uma simbiose efetiva em leguminosas tropicais cultivadas em solos ácidos (Alva et al., 1988; Brose, 1991; Taylor et al., 1991).
O objetivo deste trabalho foi verificar a necessidade da adição de calcário, e avaliar o efeito da inoculação de estirpes de rizóbio com comprovada eficácia na fixação de $\mathrm{N}$ em sabiá, cultivada em solos ácidos da Zona da Mata e do Semi-Árido do Estado de Pernambuco.

\section{MATERIAL E MÉTODOS}

Em ensaios prévios de laboratório usando cultura líquida (meio 79) em erlenmeyers de $125 \mathrm{~mL}$ com $50 \mathrm{~mL}$ do meio, foram obtidas nove estirpes com resistência a acidez. Em ensaio em vasos de Leonard com solução nutritiva (Norris, 1964), cultivados com a leguminosa arbórea sabiá, submetida a inoculação de nove estirpes de rizóbio de eficiência comprovada, foram selecionadas três com tolerância a acidez (pH 4,0) e a Al trocável $\left(40 \mathrm{mmol}_{\mathrm{c}} \mathrm{kg}^{-1}\right)$. A acidificação crescente ( $\mathrm{pH}$ de $3,8,4,0,4,2,4,4,4,6$ e 4,8) foi obtida com adição de $\mathrm{H}_{2} \mathrm{SO}_{4} 0,1 \mathrm{~N}$, e os níveis $0,0,0,5,1,0,2,0$ e $4,0 \mathrm{mg} \mathrm{kg}^{-1} \mathrm{de} \mathrm{Al}^{3+}$, com aplicação de $\mathrm{Al}_{2}\left(\mathrm{SO}_{4}\right)_{3}$. A solução nutritiva foi renovada semanalmente, e realizada avaliação do $\mathrm{pH}$ e Al na solução no final do ensaio.

No experimento em vasos com capacidade para $5 \mathrm{~kg}$, usaram-se dois solos álicos da região Nordeste, sendo um Podzólico Vermelho-Amarelo (PV) textura argilo-arenosa da Zona da Mata Úmida (Goiana, PE), e um Latossolo Vermelho-Amarelo (LV) textura franco-arenosa do Semi-Árido (Serra do Araripe, PE). Os resultados da análise de fertilidade encontram-se na Tabela 1. A calagem foi realizada nos níveis 0,3 e $6 \mathrm{t} \mathrm{ha}^{-1}$, aplicando-se calcário dolomítico com $29 \%$ de Ca, $19 \%$ de $\mathrm{Mg}$ e PRNT $=90 \%$. Os vasos permaneceram em incubação por 30 dias, com duas irrigações diárias, mantendo a umidade próxima à capacidade de campo (pote), por meio de drenagem com drenos colocados na parte inferior dos potes, e a solução drenada era retornada ao vaso por ocasião da subseqüente adição da água.

Usaram-se cinco tratamentos: inoculação das estirpes NFB 539, NFB 577 e NFB 578, selecionadas nos ensaios prévios em laboratório e em vasos Leonard, aplicadas isoladamente; fertilização com $\mathrm{NH}_{4} \mathrm{NO}_{3}$, com o nível equivalente a $100 \mathrm{~kg} \mathrm{ha}^{-1}$ de $\mathrm{N}$ e sem inoculante, e o tratamentocontrole sem inoculante e sem $\mathrm{N}$ mineral. A adubação básica com $\mathrm{P}$ e $\mathrm{K}$ foi realizada com adição de $\mathrm{KH}_{2} \mathrm{PO}_{4}$ com o nível equivalente a $60 \mathrm{~kg} \mathrm{ha}^{-1}$ de $\mathrm{P}$ e $73 \mathrm{~kg} \mathrm{ha}^{-1} \mathrm{de} \mathrm{K}$, aplicados, em dose única, uma semana antes do plantio.

A colheita foi realizada 110 dias após a emergência (DAE). As raízes foram lavadas cuidadosamente, com uso de peneira, e em seguida colocou-se o raizame em recipiente de vidro $(750 \mathrm{~mL})$, para determinação da atividade da nitrogenase por cromatografia gasosa, de acordo com a 
metodologia descrita por Hardy et al. (1973). O etileno evoluído foi calculado pela fórmula descrita por Boddey et al. (1987). Após a determinação da atividade da nitrogenase, os nódulos foram separados das raízes, contados, e conduzidos, juntamente com a parte aérea, para secagem em estufa de circulação de ar a $65^{\circ} \mathrm{C}$, até peso constante, para determinação da matéria seca.

Posteriormente, procedeu-se à moagem da parte aérea em moinho tipo Willey (peneira no 20), e determinou-se o $\mathrm{N}$ total por digestão sulfúrica, pelo método de Kjeldhal semimicro, em analisador automático Kjeltec, seguindo a metodologia descrita por Malavolta et al. (1989). Em amostras de solo determinaram-se o $\mathrm{pH}$ e o Al trocável, de acordo com metodologia da Embrapa (1997).

O experimento seguiu o esquema fatorial $2 \times 3 \times 5$, com o delineamento em blocos ao acaso, com quatro repetições. Para comparação das médias, utilizou-se o teste de Tukey a $5 \%$ de probabilidade, e foram feitas correlações entre o peso de nódulos e o $\mathrm{N}$ total na parte aérea das plantas (Döbereiner et al., 1966).

\section{RESULTADOS E DISCUSSÃO}

\section{Peso de nódulos e atividade da nitrogenase}

Observou-se, pela Tabela 2, que não ocorreu formação de nódulos no Latossolo Vermelho-Amarelo, demonstrando total ausência de rizóbio nativo e que foi bastante reduzida (em torno de 50\%) a nodulação no Podzólico Vermelho-Amarelo, o que mostra a necessidade de inoculação em solos ácidos, para uma efetiva nodulação de sabiá.

De acordo com Danso et al. (1992), além da habilidade da estirpe de promover boa nodulação em solo ácido, o genótipo da planta é muito importan- te no processo de formação dos nódulos. Chong et al. (1987) relataram que as plantas excretam diferentes exsudatos, que podem promover alterações no $\mathrm{pH}$ do solo próximo à rizosfera, possibilitando a nodulação em solos ácidos. Por outro lado, Cunningham \& Munns (1984), avaliando várias estirpes de diferentes leguminosas, observaram que as estirpes tolerantes à acidez produziram mais polissacarídeos extracelulares (EPS), independentemente da planta infectada.

No solo Podzólico Vermelho-Amarelo, o tratamento sem inoculação, com aplicação de $\mathrm{N}$ mineral $\left(100 \mathrm{~kg} \mathrm{ha}^{-1}\right)$, embora com redução em torno de $50 \%$ na nodulação, não inibiu totalmente a formação de nódulos por rizóbio nativo, o que também foi observado por Cruz et al. (1997), em jacatupé, e por Chen et al. (1992), em soja, adicionando níveis crescentes de N mineral. Stamford et al. (1995), adicionando $\mathrm{N}$ mineral, em caupi infectado com estirpes de comprovada efetividade, concluíram que esta leguminosa tropical tem boa tolerância a $\mathrm{N}$ mineral, sem redução no número e no peso dos nódulos, com níveis superiores a $100 \mathrm{~kg} \mathrm{ha}^{-1}$.

$\mathrm{A}$ adição de $3 \mathrm{t} \mathrm{ha}^{-1}$ de calcário não influenciou o peso dos nódulos (Tabela 3), o que está de acordo com o conceito de Norris (1967), o qual considera não ser necessário a calagem na grande maioria das leguminosas tropicais, fato também constatado em caupi (Stamford \& Costa, 1985; Stamford et al., 1990). De acordo com Baldani et al. (1982), a calagem pode promover um desequilíbrio microbiano no solo, levando a um aumento de actinomicetos, que pode favorecer a produção de antibióticos na rizosfera e prejudicar a nodulação.

TABELA 1. Características químicas e físicas dos solos Podzólico Vermelho-Amarelo (PV) e Latossolo Vermelho-Amarelo (LV) utilizados no experimento.

\begin{tabular}{|c|c|c|c|c|c|c|c|c|c|}
\hline \multirow[t]{2}{*}{ Solo } & \multicolumn{5}{|c|}{ Análise química ${ }^{1}$} & \multicolumn{4}{|c|}{ Análise física $^{2}$} \\
\hline & $\mathrm{pH}\left(\mathrm{H}_{2} \mathrm{O}\right)$ & $\mathrm{Al}^{3+}$ & $\mathrm{Ca}+\mathrm{Mg}$ & $\mathrm{K}$ & $\mathrm{P}$ & Areia & Silte & Argila & Densidade \\
\hline & $(1: 2,5)$ & \multicolumn{2}{|c|}{$\left(\mathrm{mmol}_{\mathrm{c}} \mathrm{kg}^{-1}\right)$} & \multicolumn{2}{|c|}{$\left(\mathrm{mg} \mathrm{kg}^{-1}\right)$} & \multicolumn{3}{|c|}{$(\%)$} & $\left(\mathrm{g} \mathrm{cm}^{-3}\right)$ \\
\hline PVA & 4,16 & 7,0 & 7,8 & 22,0 & 0,5 & 49,4 & 15,6 & 35,0 & 1,25 \\
\hline LVA & 4,44 & 5,0 & 4,0 & 20,3 & 2,8 & 86,6 & 5,2 & 8,2 & 1,33 \\
\hline
\end{tabular}

${ }_{1}^{1} \mathrm{pH}$, alumínio, cálcio + magnésio, potássio e fósforo determinados pelo método da Embrapa (1997).

2 Textura pelo método de Boyoucos e densidade das partículas pelo balão volumétrico (Allison, 1965). 
Em leguminosas tropicais, a resposta à calagem parece ser variável com a espécie, e provavelmente com a cultivar, e é possível que ocorra variação de acordo com a estirpe de rizóbio. Em soja, Arruda et al. (1968) observaram resposta à calagem em três experimentos, enquanto Fernandes (1995) não verificou efeito da calagem na soja (cultivar tropical) cultivada em solos da região Nordeste.

Hansen \& Munns (1988) comprovaram o efeito positivo da calagem em leucena, e, por outro lado, Keyser \& Munns (1979), trabalhando com estirpes do grupo caupi, resistentes a acidez, não evidenciaram resposta à adição de calcário, e Rocha \& Holanda (1983) constataram que a ausência da calagem não afetou a nodulação em estilosantes.

Em todos os níveis de calagem, os tratamentos com inoculação apresentaram maior peso de nódulos, em relação aos tratamentos não infectados; todavia, quando avaliada de maneira geral (média dos tratamentos), constatou-se que a calagem no nível mais elevado $\left(6\right.$ t ha $\left.^{-1}\right)$ reduziu a nodulação, em comparação com o tratamento com adição de 3 tha $^{-1}$ e sem adição de calcário (Tabela 3 ). As estirpes usadas não mostraram diferença significativa entre si, dentro dos diferentes níveis de calagem, o que está de acordo com os resultados de Stamford et al. (1997), com sabiá cultivada em solo ácido com diferentes níveis de P. Naidu et al. (1990) também não observaram efeito da calagem no desenvolvimento dos nódulos em leucena infectada com estirpes eficientes. Por outro lado, Carvalho et al. (1982), em estilosantes, Murphy et al. (1984), em quatro leguminosas tropicais, e Chong et al. (1987), em caupi e amendoim, mostraram que a acidez diminuiu a nodulação.

Com referência à atividade da nitrogenase, verificou-se efeito altamente significativo das estirpes inoculadas, em comparação com os tratamentos sem inoculação, dos níveis de calcário (Tabela 3) e dos solos usados (Tabela 2). Observou-se que nas plantas sem inoculação não houve efeito da calagem, provavelmente por causa da baixa atividade enzimática nos tratamentos com e sem adição de $\mathrm{N}$ mineral. De maneira geral, os melhores resultados foram obtidos com o tratamento sem adição de calcário e com o nível de $3 \mathrm{t} \mathrm{ha}^{-1}$. Entretanto, da mesma forma verificada quanto ao peso dos nódulos, encontrouse maior atividade enzimática no nível de $3 \mathrm{tha}^{-1}$, e redução dessa atividade quando adicionadas $6 \mathrm{tha}^{-1}$ de calcário. Esse efeito depressivo, quando usada calagem muito elevada, também foi observado por Stamford \& Costa (1985), em caupi, trabalhando com os mesmos solos usados no presente trabalho.

As estirpes do inoculante foram bastante efetivas, apresentando atividade da nitrogenase com valores muito superiores ao tratamento-controle sem inoculante, no caso do solo Podzólico VermelhoAmarelo, que mostrou presença de rizóbio nativo. Tais resultados evidenciam que as estirpes selecionadas para resistência a acidez foram tolerantes a $\mathrm{pH}$ próximo a 4,0 e presença de $\mathrm{Al}$ nocivo. $\mathrm{O}$ $\mathrm{N}$ mineral no nível de $100 \mathrm{~kg} \mathrm{ha}^{-1}$ não inibiu totalmen-

TABELA 2. Efeito da inoculação de rizóbio e da adição de nitrogênio, na matéria seca dos nódulos e na atividade da nitrogenase, em sabiá, em dois solos ácidos (Podzólico Vermelho-Amarelo (PV) e Latossolo Vermelho-amarelo (LV)) do Estado de Pernambuco'.

\begin{tabular}{|c|c|c|c|c|}
\hline \multirow[t]{2}{*}{ Tratamento } & \multicolumn{2}{|c|}{ Matéria seca dos nódulos (mg planta $\left.{ }^{-1}\right)$} & \multicolumn{2}{|c|}{ Ativ. da nitrogenase ( $\mu$ moles etileno planta $\left.{ }^{-1} \mathrm{~h}^{-1}\right)$} \\
\hline & PV & LV & PV & LV \\
\hline Estirpe NFB 539 & $482 \mathrm{abA}$ & $590 \mathrm{aA}$ & $7,47 \mathrm{aB}$ & $11,82 \mathrm{aA}$ \\
\hline Estirpe NFB 577 & $555 \mathrm{aA}$ & $518 \mathrm{aA}$ & $8,05 \mathrm{aB}$ & $10,81 \mathrm{aA}$ \\
\hline Estirpe NFB 578 & $552 \mathrm{aA}$ & $649 \mathrm{aA}$ & $9,24 \mathrm{aB}$ & $13,28 \mathrm{aA}$ \\
\hline Sem inoculante $+\mathrm{N}$ & $150 \mathrm{cA}$ & ObB & $1,77 \mathrm{bA}$ & $0,0 \mathrm{bB}$ \\
\hline Sem inoculante - $\mathrm{N}$ & $299 \mathrm{bcA}$ & ObB & $2,68 \mathrm{bA}$ & $0,0 \mathrm{bB}$ \\
\hline Média & $408 \mathrm{~A}$ & $351 \mathrm{~B}$ & $5,84 \mathrm{~B}$ & $7,18 \mathrm{~A}$ \\
\hline C.V. $(\%)$ & \multicolumn{2}{|c|}{37,2} & \multicolumn{2}{|c|}{36,3} \\
\hline
\end{tabular}


te a atividade da nitrogenase mesmo no solo Podzólico Vermelho-Amarelo com rizóbio nativo, sem diferença significativa nos níveis de calagem. Portanto, os resultados obtidos permitem considerar que não se faz necessária a adição de $\mathrm{N}$ mineral, nem de calagem em solos ácidos, para uma eficiente fixação do $\mathrm{N}_{2}$, quando usadas estirpes de comprovada eficiência e selecionadas para resistência a acidez.

A atividade da nitrogenase das estirpes inoculadas não apresentou diferença significativa nos dois solos; entretanto, no Latossolo Vermelho-Amarelo foram obtidos os melhores resultados. $\mathrm{O}$ fato deveu-se, provavelmente, à ausência de rizóbio nativo nesse solo, e neste caso, todos os nódulos foram formados pela estirpe do inoculante, comprovadamente mais efetiva que as naturais do solo. No Podzólico Vermelho-Amarelo, o rizóbio nativo compete com as estirpes introduzidas pelo inoculante na formação de nódulos, o que foi evidenciado por Moawad \& Bohlool (1984), em leucena, usando seis estirpes com diferentes graus de competitividade, avaliadas pelo método sorológico e imunofluorescência, e por Santillana et al. (1998), em trevovermelho, avaliadas por soroaglutinação.

\section{Nitrogênio total na parte aérea}

Houve efeito significativo da inoculação com rizóbio, em comparação com os tratamentos sem inoculação, e observou-se interação com os níveis de calagem, nos dois solos (Tabela 4). Os tratamentos sem inoculação e sem fertilização nitrogenada apresentaram $\mathrm{N}$ total na parte aérea inferior aos tratamentos com inoculação, o que demonstra a efetividade das estirpes inoculadas em sabiá. As plantas não-infectadas e sem fertilização nitrogenada foram inferiores ao tratamento com adubação nitrogenada, o que evidencia que o rizóbio nativo não foi efetivo em sabiá, como já foi verificado no tocante à nodulação. Tais resultados estão de acordo com Ribeiro Júnior et al. (1987) e Yoneyama et al. (1990), em leguminosas arbóreas, os quais constataram a elevada especificidade hospedeira em espécies da subfamília Mimosoideae.

De maneira geral, houve redução no $\mathrm{N}$ total quando feita a calagem no nível de $6 \mathrm{t} \mathrm{ha}^{-1}$, efeito este mais evidenciado nos tratamentos com inoculação. Entretanto, no que diz respeito à estirpe NFB 577, não ocorreu diferença significativa em nenhum dos níveis de calagem, o que sugere que esta estirpe é menos sensível à variação do $\mathrm{pH}$ do solo. Blair et al. (1988), trabalhando com leucena, relataram que a adição de calcário em solos ácidos aumentou a acumulação de $\mathrm{N}$ total. Por sua vez, Stamford \& Costa (1991) não observaram influência da calagem em caupi, até o nível de $6 \mathrm{t} \mathrm{ha}^{-1}$, usando os mesmos solos do presente trabalho.

A estirpe NFB 578 apresentou os melhores resultados, porém não diferiu significativamente das

TABELA 3. Efeito da calagem e da inoculação com rizóbio no peso de matéria seca dos nódulos, e na atividade da nitrogenase em sabiá, em comparação com os tratamentos sem inoculação, com e sem adição de $\mathbf{N}$ mineral ${ }^{1}$.

\begin{tabular}{lccccccc}
\hline \multirow{2}{*}{$\begin{array}{l}\text { Tratamento com } \\
\text { adição de N }\end{array}$} & \multicolumn{2}{c}{ Matéria seca dos nódulos $\left(\mathrm{mg} \mathrm{planta}^{-1}\right)$} & & \multicolumn{3}{c}{ Ativ. da nitrogenase $\left(\mu\right.$ moles etileno planta $\left.{ }^{-1} \mathrm{~h}^{-1}\right)$} \\
\cline { 2 - 3 } & Calagem 0 & Calagem 3 & Calagem 6 & & Calagem 0 & Calagem 3 & Calagem 6 \\
\hline Estirpe NFB 539 & $632 \mathrm{aA}$ & $522 \mathrm{aA}$ & $454 \mathrm{aA}$ & & $12,5 \mathrm{abA}$ & $10,2 \mathrm{aA}$ & $6,4 \mathrm{aB}$ \\
Estirpe NFB 577 & $607 \mathrm{aA}$ & $521 \mathrm{aA}$ & $482 \mathrm{aA}$ & & $10,2 \mathrm{bA}$ & $10,0 \mathrm{aA}$ & $8,2 \mathrm{aA}$ \\
Estirpe NFB 578 & $662 \mathrm{aA}$ & $732 \mathrm{aA}$ & $408 \mathrm{aA}$ & & $14,2 \mathrm{aA}$ & $13,0 \mathrm{aA}$ & $6,7 \mathrm{aB}$ \\
Sem inoculante + N & $25 \mathrm{bA}$ & $156 \mathrm{bA}$ & $43 \mathrm{bA}$ & & $0,4 \mathrm{cA}$ & $1,1 \mathrm{bA}$ & $1,1 \mathrm{bA}$ \\
Sem inoculante - N & $101 \mathrm{bA}$ & $168 \mathrm{bA}$ & $178 \mathrm{bA}$ & & $0,6 \mathrm{cA}$ & $2,0 \mathrm{bA}$ & $2,0 \mathrm{bA}$ \\
\hline Média & $406 \mathrm{~A}$ & $420 \mathrm{~A}$ & $313 \mathrm{~B}$ & $7,6 \mathrm{~A}$ & $7,2 \mathrm{~A}$ & $4,9 \mathrm{~B}$ \\
\hline C.V. $(\%)$ & \multicolumn{7}{c}{37,2} \\
\hline
\end{tabular}

${ }^{1}$ Médias com a mesma letra não diferem entre si a 5\% de probabilidade; letras maiúsculas comparam médias na linha, e minúsculas, na coluna. 
TABELA 4. Efeito da inoculação com rizóbio e da fertilização nitrogenada (100 $\left.\mathrm{kg} \mathrm{ha}^{-1}\right)$, no $\mathrm{N}$ total e na matéria seca da parte aérea de sabiá cultivada em dois solos ácidos de Pernambucoํㅜㄹ.

\begin{tabular}{|c|c|c|c|c|c|c|}
\hline \multirow[t]{2}{*}{ Tratamento } & \multicolumn{3}{|c|}{ Podzólico Vermelho-Amarelo } & \multicolumn{3}{|c|}{ Latossolo Vermelho-Amarelo } \\
\hline & Calagem 0 & Calagem 3 & Calagem 6 & Calagem 0 & Calagem 3 & Calagem 6 \\
\hline & \multicolumn{6}{|c|}{ Nitrogênio total acumulado na parte aérea (mg planta $\left.{ }^{-1}\right)$} \\
\hline Estirpe NFB 539 & $229 \mathrm{bAB}$ & $306 \mathrm{aA}$ & $216 \mathrm{abB}$ & $462 \mathrm{aA}$ & $391 \mathrm{aA}$ & $142 \mathrm{bB}$ \\
\hline Estirpe NFB 577 & $405 \mathrm{aA}$ & $321 \mathrm{aA}$ & $204 \mathrm{abcB}$ & $400 \mathrm{aA}$ & $408 \mathrm{aA}$ & $350 \mathrm{aA}$ \\
\hline Estirpe NFB 578 & $375 \mathrm{aA}$ & $325 \mathrm{aA}$ & $148 \mathrm{bcB}$ & $436 \mathrm{aA}$ & $462 \mathrm{aA}$ & $254 \mathrm{aB}$ \\
\hline Sem inoculação + N & $119 \mathrm{cB}$ & $300 \mathrm{aA}$ & $263 \mathrm{aA}$ & $80 \mathrm{bA}$ & $140 \mathrm{bA}$ & $142 \mathrm{bA}$ \\
\hline Sem inoculação - N & $72 \mathrm{cA}$ & $108 \mathrm{bA}$ & $112 \mathrm{cA}$ & $21 \mathrm{bA}$ & $17 \mathrm{cA}$ & $14 \mathrm{cA}$ \\
\hline \multirow[t]{2}{*}{ Média } & $240,3 \mathrm{~A}$ & $272,6 \mathrm{~A}$ & $189,0 \mathrm{~B}$ & $279,8 \mathrm{~A}$ & $284,8 \mathrm{~A}$ & $180,7 \mathrm{~B}$ \\
\hline & \multicolumn{6}{|c|}{ Matéria seca da parte aérea $\left(\mathrm{g}\right.$ planta $\left.^{-1}\right)$} \\
\hline Estirpe NFB 539 & $15,8 \mathrm{bA}$ & $13,7 \mathrm{bAB}$ & $11,1 \mathrm{aB}$ & $25,8 \mathrm{aA}$ & $20,4 \mathrm{bC}$ & $10,3 \mathrm{bC}$ \\
\hline Estirpe NFB 577 & $26,5 \mathrm{aA}$ & $21,4 \mathrm{aB}$ & $10,3 \mathrm{aC}$ & $22,4 \mathrm{aA}$ & $21,0 \mathrm{aA}$ & $19,1 \mathrm{aA}$ \\
\hline Estirpe NFB 578 & $27,1 \mathrm{aA}$ & $15,9 \mathrm{bB}$ & $8,3 \mathrm{aC}$ & $25,6 \mathrm{aA}$ & $24,6 \mathrm{aA}$ & $12,5 \mathrm{bB}$ \\
\hline Sem inoculação + N & $11,4 \mathrm{bA}$ & $14,3 \mathrm{bA}$ & $12,7 \mathrm{aA}$ & $7,6 \mathrm{bA}$ & $9,2 \mathrm{bA}$ & $11,0 \mathrm{bA}$ \\
\hline Sem inoculação - N & $5,4 \mathrm{cA}$ & $7,5 \mathrm{aA}$ & $7,7 \mathrm{aA}$ & $1,6 \mathrm{cA}$ & $3,5 \mathrm{cA}$ & $2,1 \mathrm{cA}$ \\
\hline Média & $17,3 \mathrm{~A}$ & $14,5 \mathrm{~B}$ & $10,0 \mathrm{C}$ & $16,6 \mathrm{~A}$ & $15,7 \mathrm{~A}$ & $11,0 \mathrm{~B}$ \\
\hline C.V. (\%) & & 18,1 & & & 18,0 & \\
\hline
\end{tabular}

estirpes NFB 539 e NFB 578, no Latossolo VermelhoAmarelo. No Podzólico Vermelho-Amarelo, as estirpes NFB 577 e NFB 578 diferiram da NFB 539, quando não se usou calagem, o que sugere que as duas estirpes são mais resistentes a alta acidez e a Al nocivo. Faria et al. (1984), selecionando estirpes efetivas em sabiá, usando vasos Leonard, não encontraram resultados tão animadores, provavelmente pela menor efetividade das estirpes usadas.

A adição de $6 \mathrm{t} \mathrm{ha}^{-1}$ de calcário provavelmente afetou não apenas o processo da fixação do $\mathrm{N}_{2}$, mas também o desenvolvimento da planta, como observado por Samarão et al. (1986), em soja, e por Stamford et al. (1990), em caupi.

Observou-se correlação significativa entre o peso de nódulos e o $\mathrm{N}$ total acumulado na parte aérea de sabiá, nos diversos níveis de calagem, nos dois solos (Tabela 5), especialmente quando usada a estirpe NFB 578, que apresentou coeficiente de correlação superior a $90 \%$.

Pesq. agropec. bras., Brasília, v.35, n.5, p.1037-1045, maio 2000
TABELA 5. Regressão entre peso de matéria seca dos nódulos e $\mathbf{N}$ total na parte aérea de sabiá infectada com as diferentes estirpes de rizóbio ${ }^{1}$.

\begin{tabular}{llc}
\hline $\begin{array}{l}\text { Estirpe de } \\
\text { rizóbio }\end{array}$ & Equação & $\begin{array}{c}\text { Coeficiente de } \\
\text { correlação }\end{array}$ \\
\hline NFB 539 & $\mathrm{Y}=60,266+0,434 \mathrm{X}$ & $\mathrm{R}=0,612^{* *}$ \\
NFB 577 & $\mathrm{Y}=146,791+0,375 \mathrm{X}$ & $\mathrm{R}=0,641^{* *}$ \\
NFB 578 & $\mathrm{Y}=12,244+0,575 \mathrm{X}$ & $\mathrm{R}=0,901^{* *}$ \\
\hline
\end{tabular}

${ }^{1}$ As equações representam dados dos dois solos, com os três níveis de calagem e quatro repetições $(n=24)$.

\section{Matéria seca da parte aérea}

Observou-se efeito significativo da inoculação de rizóbio, nos diferentes níveis de calagem, nos dois solos usados (Tabela 4). O crescimento das plantas não-infectadas e sem aplicação de $\mathrm{N}$ mineral foi reduzido, especialmente quando em comparação com 
os tratamentos que receberam inoculação de rizóbio, evidenciando o baixo teor de $\mathrm{N}$ do solo e a ineficiência ou inexistência de rizóbio nativo. Esses resultados são concordantes com os obtidos em outras leguminosas (Ribeiro Júnior et al., 1987; Costa et al., 1989). Stamford et al. (1997), trabalhando com sabiá, também mostraram o efeito da inoculação de rizóbio e de fungos micorrízicos em solo ácido com adição de diferentes fontes de P. Blair et al. (1988) comentam que a necessidade de inoculação de uma estirpe eficiente ajuda no estabelecimento e desenvolvimento das plantas, em solos com deficiência de N.

Observou-se diferença significativa entre as estirpes usadas, com relação aos níveis de calcário (Tabela 4). Todavia, a estirpe NFB 577 não apresentou diferença significativa nos níveis de calagem usados. De maneira geral, os melhores resultados foram obtidos com as estirpes NFB 577 e NFB 578, principalmente no tratamento sem adição de calcário e no nível de calagem de $3 \mathrm{t} \mathrm{ha}^{-1}$. Houve redução no peso de matéria seca da parte aérea quando se adicionaram $6 \mathrm{t} \mathrm{ha}^{-1}$ de calcário, e inoculação de rizóbio, principalmente no Latossolo VermelhoAmarelo. O efeito da inoculação foi bastante evidente, verificando-se que nas plantas sem inoculação, com e sem adição de $\mathrm{N}$ mineral, não houve resposta à calagem, nos dois solos, principalmente da parte do tratamento sem inoculação e sem adição de $\mathrm{N}$ mineral no Latossolo Vermelho-Amarelo, no qual se observou deficiência de $\mathrm{N}$, decorrente da total ausência de rizóbio nativo.

A eliminação do Al tóxico ocorreu já no nível de 3 t ha ${ }^{-1}$ de calcário mas nos dois solos, a neutralização total da acidez não foi observada, mesmo quando usado o nível de $6 \mathrm{t} \mathrm{ha}^{-1}$ (Tabela 6).

TABELA 6. Efeito dos níveis de calagem no pH e no alumínio trocável nos solos Podzólico Vermelho-Amarelo (PV) e Latossolo Vermelho-Amarelo (LV) ${ }^{1}$.

\begin{tabular}{|c|c|c|c|c|c|c|}
\hline \multirow[t]{2}{*}{ Solo } & \multicolumn{3}{|c|}{$\mathrm{pH}$ do solo $\left(\mathrm{H}_{2} \mathrm{O}-2,5: 1\right)$} & \multicolumn{3}{|c|}{$\mathrm{Al}^{3+}\left(\mathrm{mmol}_{\mathrm{c}} \mathrm{kg}^{-1}\right)$} \\
\hline & Calagem 0 & Calagem 3 & Calagem 6 & Calagem 0 & Calagem 3 & Calagem 6 \\
\hline PV & $4,0 \mathrm{aC}$ & $5,5 \mathrm{aB}$ & $6,4 \mathrm{aA}$ & $7,6 \mathrm{aA}$ & $0,00 \mathrm{aB}$ & $0,00 \mathrm{aB}$ \\
\hline LV & $4,1 \mathrm{aC}$ & $5,7 \mathrm{aB}$ & $6,7 \mathrm{aA}$ & $5,7 \mathrm{bA}$ & $0,00 \mathrm{aB}$ & $0,00 \mathrm{aB}$ \\
\hline
\end{tabular}

\section{CONCLUSÕES}

1. As estirpes selecionadas para resistência a acidez são efetivas na acumulação de nitrogênio total e no crescimento da leguminosa sabiá, em solos ácidos.

2. De maneira geral, não é necessário o uso de calcário para a leguminosa sabiá infectada com estirpes efetivas.

\section{REFERÊNCIAS}

ALLISON, L.E. Organic carbon. In: BLACK, C.A.; EVANS, D.D.; WHITE, J.L.; ENSMINGER, L.E.; CLARK, F.E. (Eds.). Methods of soil analysis. Madison : American Society of Agronomy, 1965. Part 2, p.1367-1378.

ALMEIDA, R.T.; VASCONCELOS, I.; NESS, R.L.L. Infecção micorrízica vesículo-arbuscular e nodulação de leguminosas arbóreas do Ceará, Brasil. Ciência Agronômica, Fortaleza, v.17, n.1, p.89-97, 1986.

ALVA, A.K.; EDWARDS, D.G.; CARROLL, B.J. ASHER, C.J.; GRESSHOFF, P.M. Nodulation and early growth of soybean mutants with increased nodulation capacity under acid soil infertility factors. Agronomy Journal, Madison, v.80, p.836-841, 1988.

ARRUDA, N.B.; DÖBEREINER, J.; GERMER, C.M. Inoculação, adubação e revestimento de calcário em três variedades de soja (Glycine max L. Merrill). Pesquisa Agropecuária Brasileira, Rio de Janeiro, v.3, p.201-205, 1968.

ASSIS JÚNIOR, R.N. de; ALMEIDA, R.T. de; VASCONCELOS, I. Seleção de estirpes de Rhizobium sp. em sabiá (Mimosa caesalpiniaefolia Benth). Ciência Agronômica, Fortaleza, v.17, n.2, p.101-105, 1986.

BALDANI, J.I.; BALDANI, V.L.D.; XAVIER, D.F.; BODDEY, R.M.; DÖBEREINER, J. Efeito da calagem no número de actinomicetos e na porcentagem de bactérias resistentes à estreptomicina na rizosfera de milho, trigo e feijão. Revista de Microbiologia, São Paulo, v.13, n.3, p.250-263, 1982.

BÊDE, S.N.P.; FROTA, J.N.E.; VASCONCELOS, I.; ALVES, J.F. Identificação de fatores nutricionais limitantes da fixação simbiótica do nitrogênio atmosférico em leucena. Revista Brasileira de Ciência do Solo, Campinas, v.9, p.5-7, 1985.

Pesq. agropec. bras., Brasília, v.35, n.5, p.1037-1045, maio 2000 
BLAIR, G.I.; LITHGOW, K.B.; ORCHARD, P.W. The effects of $\mathrm{pH}$ and calcium on the growth of Leucaena leucocephala in an oxisol and ultisol soil. Plant and Soil, Dordrecht, v.106, p.209-214, 1988.

BODDEY, R.M.; PEREIRA, J.A.R.; HUNGRIA, M.; THOMAS, R.J.; NEVES, M.C.P. Methods for the study of nitrogen assimilation and transport in grain legumes. Journal of Applied Microbiology and Biotechnology, Oxford, v.3, p.3-37, 1987.

BROSE, E. Seleção de rizóbio tolerante a $\mathrm{Al}$ e a baixo $\mathrm{pH}$. Pesquisa Agropecuária Brasileira, Brasília, v.26, n.1, p.125-136, jan. 1991.

CARVALHO, M.M. de; EDWARDS, D.G.; ASHER, C.S.; ANDREW, C.S. Effects of aluminium on nodulation of two Stylosanthes species grown in nutrient solution. Plant and Soil, Dordrecht, v.64, p.141$152,1982$.

CHEN, H.; RICHARDSON, A.E.; GARTNER, E.; DJORDJEVIC, M.A.; ROUGHLEY, R.J.; ROLFE, B.G. Construction of an acid-tolerant Rhizobium leguminosarum biovar trifolii strain with enhanced capacity for nitrogen fixation. Applied Environmental Microbiology, Baltimore, v.57, n.7, p.2005-2011, 1991.

CHEN, Z.; MACKENZIE, A.F.; FANOUS, M.A. Soybean nodulation and grain yield as influenced by $\mathrm{N}$ : fertilizer rate, plant population of city and cultivar in Southern Quebec. Canadian Journal of Plant Science, Ottawa, v.72, n.4, p.1049-1056, 1992.

CHONG, K.; WYNNE, J.C.; ELKAN, G.H.; SCHNEEWEIS, M. Effects of soil acidity and aluminium content on Rhizobium inoculation, growth and nitrogen fixation of peanuts and other grain legumes. Tropical Agriculture, Guildford, v.64, n.2, p.97-104, 1987.

COSTA, N.L.; PAULINO, V.T.; SCHAMMAS, E.A. Produção de forragem, composição mineral e nodulação do guandu afetadas pela calagem e adubação fosfatada. Revista Brasileira de Ciência do solo, Campinas, v.13, p.51-58, 1989.

CRUZ, O.N.; STAMFORD, N.P.; SILVA, J.A.A.; CHAMBER-PEREZ, M. Effects of inoculation with Bradyrhizobium and urea application on nitrogen fixation and growth of yam bean (Pachyrhizus erosus) as affected by phosphorus fertilizers in an acid soil. Tropical Grasslands, Saint Lucia, v.35, p.23-27, 1997.
CUNNINGHAM, S.D.; MUNNS, D.N. The correlation between extracellular polysaccharide production and acid tolerance in Rhizobium. Soil Science Society of American. Journal, Madison, v.48, p.1273-1276, 1984.

DANSO, S.K.A.; BOWEN, G.D.; SANGINGA, N. Biological nitrogen fixation in trees in agro-ecosystems. Plant and Soil, Dordrecht, v.141, n.1/2, p.177-196, 1992.

DE-POLLI, H.; FRANCO, A.A.; ALMEIDA, D.L.; DUQUE, F.F.; MONTEIRO, E.M. da; DÖBEREINER, J. A biologia do solo na agricultura. Rio de Janeiro : Embrapa-UAPNPBS, 1988. 48p. (EmbrapaUAPNPBS. Documentos, 5).

DÖBEREINER, J.; ARRUDA, N.B.; PENTEADO, A.F Avaliação da fixação do nitrogênio, em leguminosas, pela regressão do nitrogênio total das plantas sobre o peso de nódulos. Pesquisa Agropecuária Brasileira, Rio de Janeiro, v.1, p.233-237, 1966.

DUGUMA, B.; KANG, B.T.; OKALI, D.U.U. Effect of liming and phosphorus application on performance of Leucaena leucocephala in acid soils. Plant and Soil, Dordrecht, v.110, p.57-61, 1988.

EMBRAPA. Centro Nacional de Pesquisa de Solos (Rio de Janeiro, RJ). Manual de métodos de análises de solos. 2.ed. rev. Rio de Janeiro, 1997. 212p.

FARIA, S.M.; MOREIRA, V.C.G.; FRANCO, A.A. Seleção de estirpes de Rhizobium para espécies de leguminosas florestais. Pesquisa Agropecuária Brasileira, Brasília, v.19, s/n, p.175-179, jun. 1984. Edição Especial.

FERNANDES, A.S. Efeito do calcário e do composto urbano na fixação do $\mathrm{N}_{2}$ e produção de matéria seca da soja (Glycine max cv. tropical) cultivada em Latossolo Vermelho-Amarelo álico. Recife : UFRPE, 1995. 111p. Dissertação de Mestrado.

HANSEN, E.H.; MUNNS, D.N. Effects of $\mathrm{CaSO}_{4}$ and $\mathrm{NaCl}$ on growth and nitrogen fixation of Leucaena leucocephala. Plant and Soil, Dordrecth, v.107, p.95-99, 1988

HARDY, R.W.F.; BURNS, R.C.; HOLSTEN, R.D. Application of the acetylene-ethylene assay for measurement of nitrogen fixation. Soil Biology \& Biochemistry, Elmsford, v.5, p.47-81, 1973.

KEYSER, H.H.; MUNNS, D.N. Tolerance of rhizobia to acidity, aluminum, and phosphate. Soil Science 
Society of America. Journal, Madison, v.43, p.519-523, 1979.

MALAVOLTA, E.; VITTI, G.C.; OLIVEIRA, S.A. de. Avaliação do estado nutricional das plantas: princípios e aplicações. Piracicaba : Associação Brasileira para Pesquisa da Potassa e do Fosfato, 1989. 201p.

MOAWAD, H.; BOHLOOL, B.B. Competition among Rhizobium spp. for nodulation of Leucena leucocephala in two tropical soils. Applied Environmental Microbiology, Baltimore, v.48, p.5-9, 1984.

MURPHY, H.E.; EDWARDS, D.G.; ASHER, C.J. Effects of aluminium on nodulation and early growth of four tropical pasture legumes. Australian Journal of Agricultural Research, Melbourne, v.35, p.663673, 1984.

NAIDU, R.; TILLMAN, R.W.; SYERS, J.K.; KIRKMAN, J.H. Lime - aluminium - phosphorus interactions and the growth of Leucaena leucocephala. Plant and Soil, Dordrecth, v.126, n.1, p.9-17, 1990.

NORRIS, O.D. The intelligent use of inoculants and lime peletting for tropical legumes. Tropical Grasslands, Saint Lucia, v.1, p.107-121, 1967.

NORRIS, O.D. Some concepts and methods in sub tropical pasture research. Maidenhead: Commonwealth Bureau of Pasture and Field Crops, 1964. 65p. (Bulletin, 47).

RIBEIRO JÚNIOR, W.Q.; LOPES, E.S.; FRANCO, A.A eficiência de estirpes de Bradyrhizobium spp. para quatro leguminosas arbóreas e competitividade das estirpes em Albizia lebbek em latossolo ácido. Revista Brasileira de Ciência do Solo, Campinas, v.11, p.275-282, 1987.

ROCHA, R.R.; HOLANDA, F.J.M. Efeitos da nutrição mineral e da inoculação na fixação simbiótica do nitrogênio atmosférico em Stylosanthes humata (L.) Taub. cv. Verano. Ciência Agronômica, Fortaleza, v.14, n.1/2, p.97-105, 1983.

SAMARÃO, S.S.; DIDONET, A.D.; NEIVA, L.C.S.; DUQUE, F.F.; GOI, S.R.; JACOB NETO, J.; MONTEIRO, P.M.F.O.; ROLIM, R.B. Influência da calagem e micronutrientes na nodulação da soja por Rhizobium japonicum em solos ácidos. Pesquisa Agropecuária Brasileira, Brasília, v.21, n.3, p.237-244, mar. 1986.
SANTILLANA, N.; FREIRE, J.R.J.; SÁ, E.L.S.; SATO, M. Avaliação de estirpes de rizóbio para a produção de inoculantes para trevo vermelho. Revista Brasileira de Ciência do Solo, Campinas, v.22, p.231-237, 1998.

SIQUEIRA, J.O. Nutritional and edhaphic factors affecting spores germination, germ tube and root colonization by vesicular-arbuscular mycorrhizal fungi. Gainesville : University of Florida, 1983. 159p. Ph.D. Thesis.

STAMFORD, N.P.; CHAMBER-PEREZ, M.; CAMACHO-MARTINEZ, M. Symbiotic effectiveness of several tropical Bradyrhizobium strains on cowpea under a long-term exposure to nitrate: relationships between nitrogen fixation and nitrate reduction activities. Journal of Plant Physiology, Stuttgart, v.147, p.378-382, 1995.

STAMFORD, N.P.; COSTA, J.P.V. Efeito de fontes, níveis e granulometria de calcários na fixação do $\mathrm{N}_{2}$ e no estado nutricional de caupi. Ciência Agronômica, Maceió, v.1, p.37-48, 1991.

STAMFORD, N.P.; COSTA, J.P.V. Efeito de níveis e granulometria de calcários na fixação do $\mathrm{N}_{2}$ e na produção de matéria seca de caupi. Agronomia Sulriograndense, Porto Alegre, v.21, p.123-134, 1985.

STAMFORD, N.P.; ORTEGA, A.D.; TEMPRANO, F.; SANTOS, D.R. Effects of phosphorus fertilization and inoculation of Bradyrhizobium and mycorrhizal fungi on growth of Mimosa caesalpiniaefolia in an acid soil. Soil Biology \& Biochemistry, Elmsford, v.29, p.959-964, 1997.

STAMFORD, N.P.; VIEIRA, I.M.M.B.; SANTOS, D.R.; SANTOS, C.E.R. Seleção de Bradyrhizobium para caupi cultivada em solo ácido do semi-árido do Brasil. Pesquisa Agropecuária Brasileira, Brasília, v.25, n.4, p.545-552, abr. 1990.

TAYLOR, R.W.; WILLIAMS, M.L.; SISTANI, K.R. N fixation by soybean - Bradyrhizobium combinations under acidity, low $\mathrm{P}$ and high $\mathrm{Al}$ stresses. Plant and Soil, Dordrecht, v.131, n.2, p.293-300, 1991.

YONEYAMA, T.; MURAKAMI, T.; BOONKERD, N.; WADISIRISUK, P.; SIRIPIN, S.; KOUNO, K. Natural ${ }^{15} \mathrm{~N}$ abundance in shrub and tree legumes, casuarina and non $\mathrm{N}_{2}$ fixing plants in Thailand. Plant and Soil, Dordrecht, v.128, p.287-292, 1990. 